\title{
Kinetic Modeling for Microwave-Enhanced Degradation of Methylene Blue Using Manganese Oxide
}

\author{
Wen-Hui Kuan, ${ }^{1}$ Chun-Yuan Chen, ${ }^{1}$ Ching-Yao $\mathrm{Hu}^{,}{ }^{2}$ and Yu-Min Tzou ${ }^{3}$ \\ ${ }^{1}$ Department of Safety, Health, and Environmental Engineering, Ming Chi University of Technology, 84 Gung-Juan Road, \\ Taishan, New Taipei 24301, Taiwan \\ ${ }^{2}$ School of Public Health, Taipei Medical University, 250 Wu-Hsing Street, Taipei 110, Taiwan \\ ${ }^{3}$ Department of Soil and Environmental Science, National Chung Hsing University, 250 Kuo-Kuang Road, Taichung 40227, Taiwan
}

Correspondence should be addressed to Wen-Hui Kuan; whkuan@mail.mcut.edu.tw

Received 19 September 2012; Revised 13 December 2012; Accepted 13 December 2012

Academic Editor: Jafar Soltan

Copyright (C) 2013 Wen-Hui Kuan et al. This is an open access article distributed under the Creative Commons Attribution License, which permits unrestricted use, distribution, and reproduction in any medium, provided the original work is properly cited.

\begin{abstract}
This study was originally performed to compare the $\mathrm{MnO}_{2}$-based degradation of aqueous methylene blue (MB) under microwave irradiation- (MW-) enhanced and conventional heating- (CH-) enhanced conditions. The degradation process and kinetics were investigated to elucidate the microwave effect on the reaction. The results showed that all three tested conditions, sole $\mathrm{MnO}_{2}$, $\mathrm{MnO}_{2} / \mathrm{CH}$, and $\mathrm{MnO}_{2} / \mathrm{MW}$, followed the third-order (second upon $\mathrm{MB}$ and first upon $\mathrm{MnO}_{2}$ ) kinetic model. However, a higher degradation rate of $\mathrm{MB}$ was available under the MW-enhanced process, which implies that the "athermal effect" of MW might be of more benefit for the generation of electrophilic oxygen ions $\left(\mathrm{O}_{2}{ }^{-}, \mathrm{O}^{-}\right.$, and $\left.\mathrm{O}^{2-}\right)$ to degrade $\mathrm{MB}$. The results showed that the degradation percentage of $\mathrm{MB}$ could reach $100 \%$, corresponding to $92 \%$ total organic carbon (TOC) removal under microwave irradiation at $\mathrm{pH} 7.20$ for $10 \mathrm{~min}$.
\end{abstract}

\section{Introduction}

Approximately 10000 various industrial dye and pigments and over $7 \times 10^{5}$ tons of these dyes are annually produced worldwide [1]. Consequently, the acute impact on the ecosystem arising from dyes and pigments released into wastewater is inevitable. Methylene blue (MB), a type of thiazine dye, is widely used as a photosensitizer commonly employed in solar cells, a photodynamic antimicrobial agent in biological materials, a test compound in semiconductor photocatalysis, and a surface modifier of semiconductor colloids [2-4]. Other than a marked quantity of colorful wastewater generated from various industrial processes, the biodegradable resistance of $\mathrm{MB}$ suggests that physicochemical treatments are indispensable for effectively controlling pollution $[5,6]$.

Microwave (MW) irradiation as an activation source for chemical reactions has been studied recently. Because most organic compounds do not absorb electromagnetic energy in the S-band $(2.4 \mathrm{GHz})$ of the MW extent [7], applying materials that absorb considerable MW and then effectively transfer this energy to reactants is inevitable [8]. According to the Poynting formulation, the time-averaged dissipated power density $P_{\text {diss. }}(d)$ at any position $d$ within lossy material is given by

$$
P_{\text {diss. }}(d)=\frac{1}{2} \omega \varepsilon_{0} \varepsilon_{d}^{\prime \prime} \vec{E}(d)^{*} \vec{E}(d)
$$

where $\omega$ is the angular frequency, $\varepsilon_{0}$ is the dielectric permittivity of vacuum, $\varepsilon_{d}^{\prime \prime}$ is the dielectric loss, and $\vec{E}(d)^{*}$ is the electric field strength; the dissipation of MW energy results in heating of the irradiated medium [9]. Heating is a conventional method for activating chemical reagents, and the significance of temperature on chemical reaction rate is well known. Except for the thermal effect on a medium, MW could allow an induced organization in an irradiated medium, called the "athermal effect," "nonthermal," or "specific effect" of electromagnetic irradiation [10]. The level of coupling with the electric field of MW radiation relies on the dielectric constant of the material. The dielectric constant determines the ability of the material to be polarized by an electric field [10]. Rapid heating arises from interaction of 
MW with either dipolar molecules or ionic species [9]. Some researchers believe that acceleration of MW-enhanced reaction rates may be attributed to a distinct mode of transferring heat to reactants and mediums; however, others believe that absorption of MW radiation has a specific athermal effect on MW-absorbing molecules. The reasons for the so-called athermal effect must be fully understood and explored [11].

Manganese oxide $\left(\mathrm{MnO}_{2}\right)$ has been reported to have a high dielectric constant of nearly 10000 [12]; therefore, excellent coupling with MW radiation can be expected. MW irradiation may produce interesting effects in comparison with conventional heating $(\mathrm{CH})$. In natural soil and aquatic environments, $\mathrm{MnO}_{2}$ plays a crucial role in governing the mobility and toxicity of numerous organic and inorganic compounds because of the various oxidation states of manganese [13, 14]. With excellent semiconductivity, porosity, and mixed-valent properties, $\mathrm{MnO}_{2}$ has been used or synthesized recently as a catalyst by the reoxidation of manganese from a lower valence to a higher valence in many technological applications $[15,16]$.

Numerous studies have reported the photocatalytic decomposition of $\mathrm{MB}$ on $\mathrm{TiO}_{2}[17,18]$ and the adsorption of $\mathrm{MB}$ onto various materials $[19,20]$. Few studies have focused on the oxidative degradation of MB using manganese oxide during a spontaneous reaction $[21,22]$. However, no previous study has described the $\mathrm{MW}$-enhanced $\mathrm{MnO}_{2}$ catalytic reaction and explored the athermal effect of $\mathrm{MW}$ on MB degradation. Hence, strict comparisons among reactions performed under similar conditions, such as the reaction medium, temperature, time, and open/closed vessel for MW-enhanced $\mathrm{MnO}_{2}\left(\mathrm{MnO}_{2} / \mathrm{MW}\right), \mathrm{CH}$-enhanced $\mathrm{MnO}_{2}\left(\mathrm{MnO}_{2} / \mathrm{CH}\right)$, and sole $\mathrm{MnO}_{2}$ systems, were studied.

\section{Material and Methods}

2.1. Chemicals. $\mathrm{MB}\left(\mathrm{C}_{16} \mathrm{H}_{18} \mathrm{~N}_{3} \mathrm{SCl}\right.$, Riedel-deHaen), azure A (Standard Fluka for microscopy), azure B (certified by the Biologic Stain Commission), azure C (certified by the Biologic Stain Commission), and thionin (Standard Fluka for microscopy) were used without further purification. All chemicals used in this study were of AnalaR grade, and the solutions were prepared with ultrapure water produced using a Milli-Q water purification system (Milli-QAcademic, Millpen RIOS16). The used $\mathrm{MnO}_{2}$ particles were purchased from TOSOH Co. and confirmed to be pyrolusite, a $1 \times 1$ tunneled (or molecular sieve) structure, by using an X-ray diffractometer (XRD, Philips PANalytical X'pert PRO MPD). The surface area, porosity, and charge of $\mathrm{MnO}_{2}$ were measured using a surface analyzer (Micrometrics ASAP 2010), porosity analyzer (Micrometrics ASAP 2010), and electrophoresis instrument (Malvern Nano-ZS90), respectively. The results are shown in Table 1 . In Table 2, the literature values of dielectric constants for each material in reference to a vacuum and the temperature and the frequency at which they were measured are given.

2.2. Experimental Procedure. $\mathrm{MB}$ removal using $\mathrm{MnO}_{2}$ was performed in a $125 \mathrm{~mL}$ Erlenmeyer flask. Before the batch experiments, the $\mathrm{MnO}_{2}$ suspensions were aged at room
Table 1: The measured physicochemical properties of $\mathrm{MnO}_{2}$.

\begin{tabular}{lc}
\hline Surface area $\left(\mathrm{m}^{2} / \mathrm{g}\right)^{\mathrm{a}}$ & 46 \\
Pore volume $\left(\mathrm{cm}^{3} / \mathrm{g}\right)^{\mathrm{b}}$ & 0.11 \\
Pore width $(\mathrm{nm})^{\mathrm{c}}$ & 9.23 \\
$\mathrm{pH}_{\mathrm{zpc}}{ }^{\mathrm{d}}$ & 4.70 \\
\hline
\end{tabular}

BET surface area.

${ }^{\mathrm{b}}$ Total pore volume.

${ }^{\mathrm{c}}$ Adsorption average pore width ( $4 \mathrm{~V} / \mathrm{A}$ by BET).

${ }^{\mathrm{d}}$ Zero-point charge of $\mathrm{pH}$.

TABLE 2: Dielectric constant of materials used in this study.

\begin{tabular}{lccc}
\hline Material & Dielectric constant & $T\left({ }^{\circ} \mathrm{C}\right)$ & $v(\mathrm{~Hz})$ \\
\hline $\mathrm{MnO}_{2}$ & $10000[12]$ & 25 & $10^{4}$ \\
$\mathrm{MB}$ & $6[24]$ & 50 & $10^{2}-10^{5}$ \\
$\mathrm{HNO}_{3}$ & $50[25]$ & 14 & $10^{6}-10^{11}$ \\
$\mathrm{NaOH}$ & $58[25]$ & 25 & $10^{6}-10^{11}$ \\
Water & $80[25]$ & 20 & $10^{14}$ \\
\hline
\end{tabular}

temperature under an $\mathrm{N}_{2}$ atmosphere overnight. The initial concentration of $\mathrm{MB}$ was $10 \mathrm{mgL}^{-1}$. The $\mathrm{MnO}_{2}$ concentration was maintained at $2 \mathrm{gL}^{-1}$, and the reacting volume of solution was $100 \mathrm{~mL}$. The test solutions were adjusted to the desired $\mathrm{pH}$ (pH meter, $\mathrm{HACH}$ Sension 156) using dilute $\mathrm{NaOH}$ and $\mathrm{HNO}_{3}$ solution. System $\mathrm{pH}$ was not controlled during the reaction process because both organic and inorganic buffer agents might be oxidized, which could significantly influence $\mathrm{MB}$ degradation [23]. The $\mathrm{pH}$ during the reaction was not monitored but measured after each batch reactor was taken at the specific reaction time because the $\mathrm{pH}$ electrode interferes with MW irradiation.

The MW apparatus (CEM, MARS-5) with a frequency of $2450 \mathrm{MHz}$ used in this study had an adjustable power setting and monitored temperature. The Erlenmeyer flask containing $\mathrm{MB}$ and $\mathrm{MnO}_{2}$ suspension was cap sealed with paraffin film and placed on the rotary table in the MW oven as a batch treatment; each batch reactor was taken at a specific reaction time prior to solution analyses. To clarify the effect of temperature and electromagnetic wave on the reaction, a parallel experiment using a conventional electric heater was also conducted. The Erlenmeyer flask containing the same suspension and pretreatment was placed into a watercirculating temperature-controlled shaker, maintained at 25 and $50^{\circ} \mathrm{C}$, and gently stirred at $100 \mathrm{rpm}$ (Firstek Model-B603 $\mathrm{DL})$ to stimulate the rotator in the microwave oven.

At the desired time, a flask was taken from the microwave oven or temperature-controlled shaker, cooled, and then the suspension $\mathrm{pH}$ was measured. This represented the reaction $\mathrm{pH}$. Immediately, the suspension was filtrated through a Millipore membrane filter with a pore size of $0.2 \mu \mathrm{m}$. The filtrates were pretreated for various analyses and stored at $4^{\circ} \mathrm{C}$. All experiments were conducted in duplicate, and all data presented were the averages of duplicate analyses.

2.3. Analytical Methods. To determine the change of $\mathrm{MB}$ concentration in the solution following the reaction, a UV-vis 
spectrometer (Varian Cary 50 Bio) is often used as the major instrument. Generally, two types of information can be extracted from UV-vis analysis results. Identification of the specific molecules is based on the characteristic absorbance peaks in the UV-vis spectra in a full scan, and determining the concentration of the specific molecule is based on the absorbance intensity of the characteristic peak. The degradation or removal of MB was substantially determined by the intensity of absorbance peaks at $665 \mathrm{~nm}$. However, the possible intermediates or products were rarely identified according to the shift of characteristic absorbance peaks, which can be obtained using the full scan of UV-vis wavelengths $[23,26]$. Therefore, two data types of UV-vis spectra were extracted to speculate reactions in this study. First, the absorbance at $665 \mathrm{~nm}$ has been a prevalent method used to represent the $\mathrm{MB}$ concentration in previous studies and was used in this study. Second, because MB could be transformed or degraded to other forms of organic compounds in reaction with $\mathrm{MnO}_{2}$, using the full UV-vis wavelength scan was necessary. The total organic carbon (TOC) of the sample was determined using a TOC analyzer (O-I, Carbon Model 1010).

\section{Results and Discussion}

3.1. Effect of MW Power on the Solution Temperature. MW radiation interacts with materials of high dielectric constant and consequently leads to volumetric heating. Water is an excellent medium for MW-enhanced chemical reactions because of its high dielectric constant. Figure 1 shows the evolution of measured temperatures for MB solution under varying powers of MW radiation. The measured temperature in the $\mathrm{MB}$ solution increased with both time and MW power. The heating rate of MW was calculated from the slope of linear regression of temperature from 1 to $10 \mathrm{~min}$ in Figure 1, and being $1.6,2.9$, and $5.0^{\circ} \mathrm{C} / \mathrm{min}$ for $100 \mathrm{~W}, 200 \mathrm{~W}$, and $300 \mathrm{~W}$, respectively. At $20 \mathrm{~min}$ the temperature reached $55^{\circ} \mathrm{C}, 75^{\circ} \mathrm{C}$, and $90^{\circ} \mathrm{C}$ under $100 \mathrm{~W}, 200 \mathrm{~W}$, and $300 \mathrm{~W} \mathrm{MW}$ irradiation, respectively. To refrain from overvolatilizing the water during the reaction, the $200 \mathrm{~W}$ MW and a maximum of $10 \mathrm{~min}$ of reaction time were used to compare with conventional heating at $50^{\circ} \mathrm{C}$ in the following experiments.

3.2. Spectra of Full UV-Vis Wavelength Scan. To compare the degradation efficiency, the UV-vis absorption spectra of MB treated under various conditions at $\mathrm{pH} 4.75$ for $10 \mathrm{~min}$ are shown in Figure 2. The absorbance of UV-vis $665 \mathrm{~nm}$ was used to evaluate the $\mathrm{MB}$ quantity in the solution because the maximal absorbance peak occurred at this spectrum. The absorbance of $\mathrm{MB}$ treated under MW irradiation without $\mathrm{MnO}_{2}$ is similar to that of the original MB solution, implying that sole $200 \mathrm{~W}$ MW irradiation is unable to degrade MB. The peak absorbance of $\mathrm{MB}$ treated with $\mathrm{MnO}_{2}$ at $25^{\circ} \mathrm{C}$ decreases by approximately $60 \%$, and the higher heating temperature results in the more declination of absorbance peak for $\mathrm{MB}$. For conventional heating at $50^{\circ} \mathrm{C}(\mathrm{CH})$, the corresponding degradation ratio is approximately $85 \%$. In contrast, the absorption peak at UV-vis $665 \mathrm{~nm}$ descends significantly by 99\% under the $\mathrm{MnO}_{2} / \mathrm{MW}$ system. The solution temperature

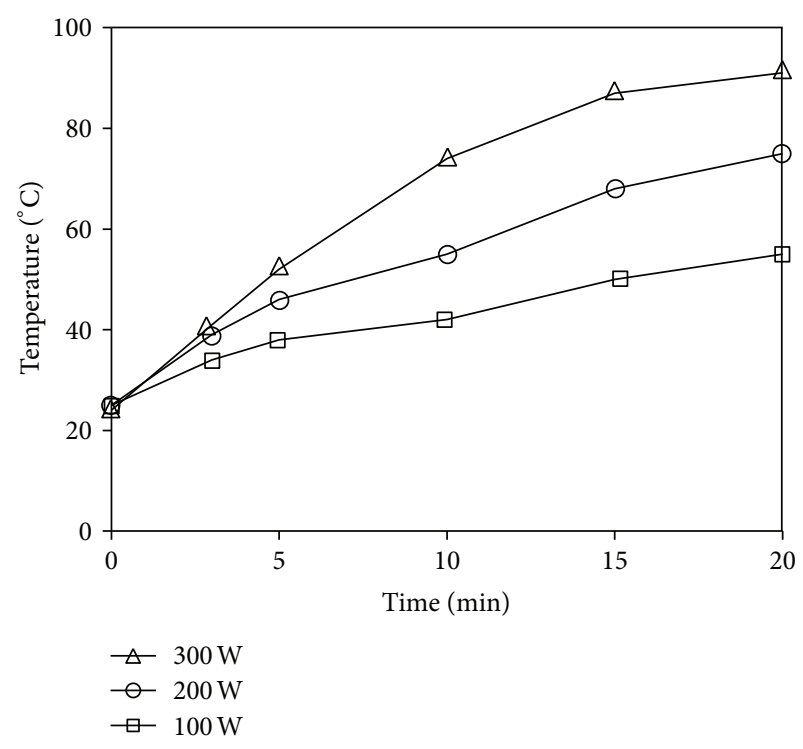

FIGURE 1: Effects of MW power on MB-containing solution temperature changes with time.

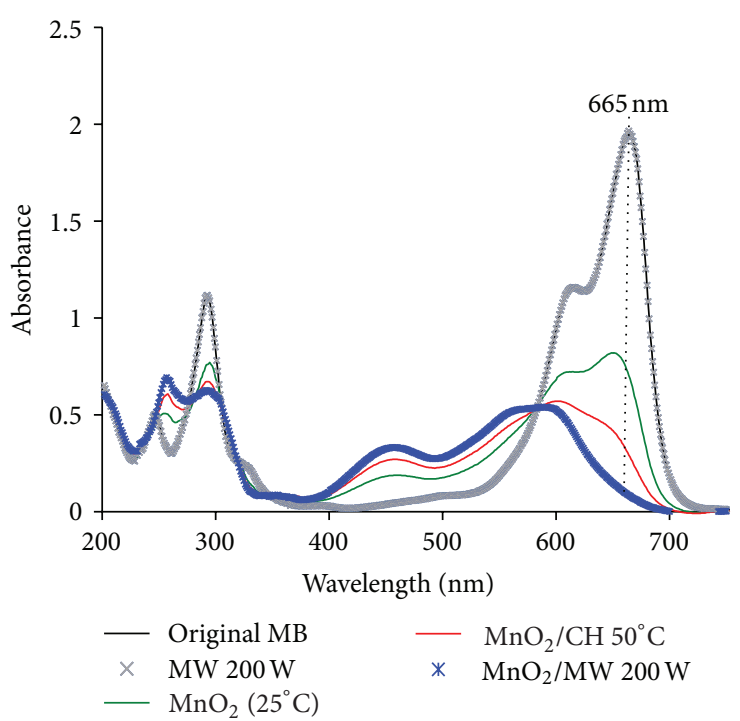

FIGURE 2: UV-vis absorption spectrogram of MB solution; $[\mathrm{MB}]=$ $10 \mathrm{mg} / \mathrm{L}(31.3 \mu \mathrm{M}),\left[\mathrm{MnO}_{2}\right]=2 \mathrm{~g} / \mathrm{L}$, reaction time $10 \mathrm{~min}$, solution $\mathrm{pH} 4.75$.

of the MW system gradually elevates to approximately $50^{\circ} \mathrm{C}$ at $10 \mathrm{~min}$. The solution temperature is lower than $50^{\circ} \mathrm{C}$ during most of the reaction time, and the degradation of $\mathrm{MB}$ in the $\mathrm{MnO}_{2} / \mathrm{MW}$ system is more pronounced than that of $\mathrm{MnO}_{2} / \mathrm{CH}$ during the entire reaction period. In $\mathrm{CH}$ process, energy is transferred through thermal gradients, whereas MW is the transfer of electromagnetic energy to thermal energy and is energy form conversion, rather than heat transfer. Therefore, MW can penetrate materials and deposit energy; heat can be generated throughout the volume of the material and is temperature independent. Because the energy delivery doses do not rely on diffusion of heat 


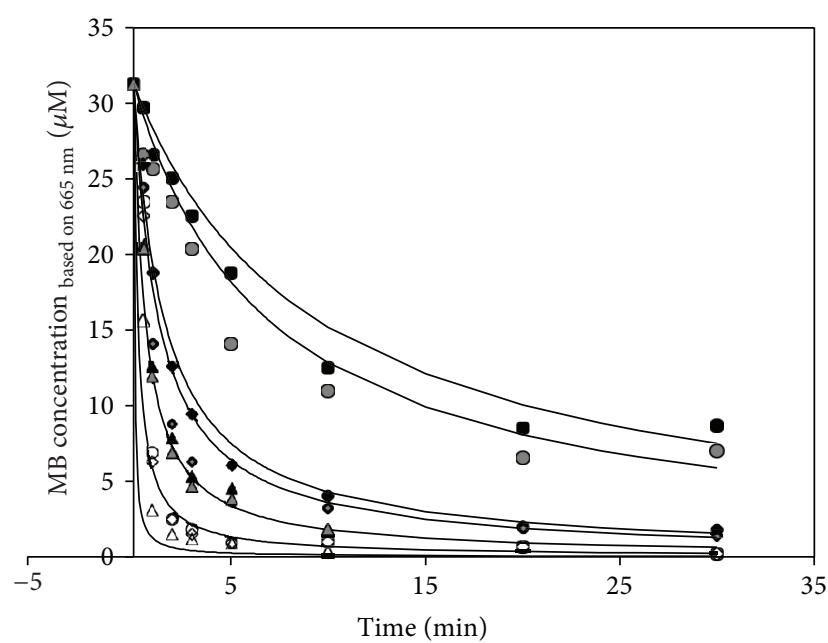

$\begin{array}{ll}\bullet \mathrm{MnO}_{2} 2.17 & \Delta \mathrm{MnO}_{2} / \mathrm{MW} \_4.75 \\ \bullet \mathrm{MnO}_{2} / \mathrm{CH} 2.17 & \bigcirc \mathrm{MnO}_{2} \text { 7.2 } \\ \Delta \mathrm{MnO}_{2} / \mathrm{MW} \_2.17 & \diamond \mathrm{MnO}_{2} / \mathrm{CH} 7.2 \\ \circ \mathrm{MnO}_{2} \text { 4.75 } & \triangle \mathrm{MnO}_{2} / \mathrm{MW}_{-} 7.2 \\ \diamond \mathrm{MnO}_{2} / \mathrm{CH} \mathrm{MH}_{-} .75 & \end{array}$

FIGURE 3: Kinetics of MB degradation and the third-order kinetic model (line).

from the material surfaces, MW can achieve instantaneous heating of materials. Synergistic effects of $\mathrm{MW}$ and $\mathrm{MnO}_{2}$ on the degradation of $\mathrm{MB}$ can be concluded. A marked blue shift of the main absorption peak from UV-vis $665 \mathrm{~nm}$ to $600 \mathrm{~nm}$ was observed for the $\mathrm{MnO}_{2} / \mathrm{MW}$ system at $10 \mathrm{~min}$. The phenomenon suggests that $\mathrm{MB}$ was degraded and new intermediates were generated in the solution.

3.3. Kinetics of $M B$ Degradation. Figure 3 shows the kinetics of $\mathrm{MB}$ degradation profiles using sole $\mathrm{MnO}_{2}$, enhanced by $\mathrm{CH}$, or enhanced by $\mathrm{MW}$ at various $\mathrm{pH}$ values. $\mathrm{MB}$ shows a sharp decline in the initial $5 \mathrm{~min}$ of reaction time and significant $\mathrm{pH}$-dependent degradation. The experiment conducted at a pH of 2.17 in the system of sole $\mathrm{MnO}_{2}$ and $\mathrm{MnO}_{2} / \mathrm{CH}$ shows a lower $\mathrm{MB}$ degradation, compared with other systems; however, at the same $\mathrm{pH}, \mathrm{MB}$ degradation is considerably enhanced by $\mathrm{MW}$ irradiation $\left(\mathrm{MnO}_{2} / \mathrm{MW}\right)$ and approaches approximately $92 \%$ removal in the initial $2 \mathrm{~min}$. Our previous research showed that $\mathrm{MB}$ displays a lower removal beneath $\mathrm{pH}_{\mathrm{zpc}}$ of $\mathrm{MnO}_{2}$ (4.70) because cationic $\mathrm{MB}$ was weakly adsorbed onto the positively charged $\mathrm{MnO}_{2}$ surface [27]. When under system $\mathrm{pH}$ is beyond the $\mathrm{pH}_{\mathrm{zpc}}$, strong affinity between cationic $\mathrm{MB}$ and negatively charged $\mathrm{MnO}_{2}$ exerts $\mathrm{MB}$ degradation [28] because heterogeneous degradation initiates with the formation of a precursor complex between target contaminants and surface-bound Mn $[29,30]$. In addition, the oxidative degradation of $M B$ must be coupled with a half reduction reaction. Two possible reduction reactions in this system are dissolved oxygen (DO) reduction and $\mathrm{MnO}_{2}$-reduced dissolution. It has been well known that organics are oxidatively degraded by $\mathrm{MnO}_{2}$ via a surface mechanism. The firstly adsorbed organic compound

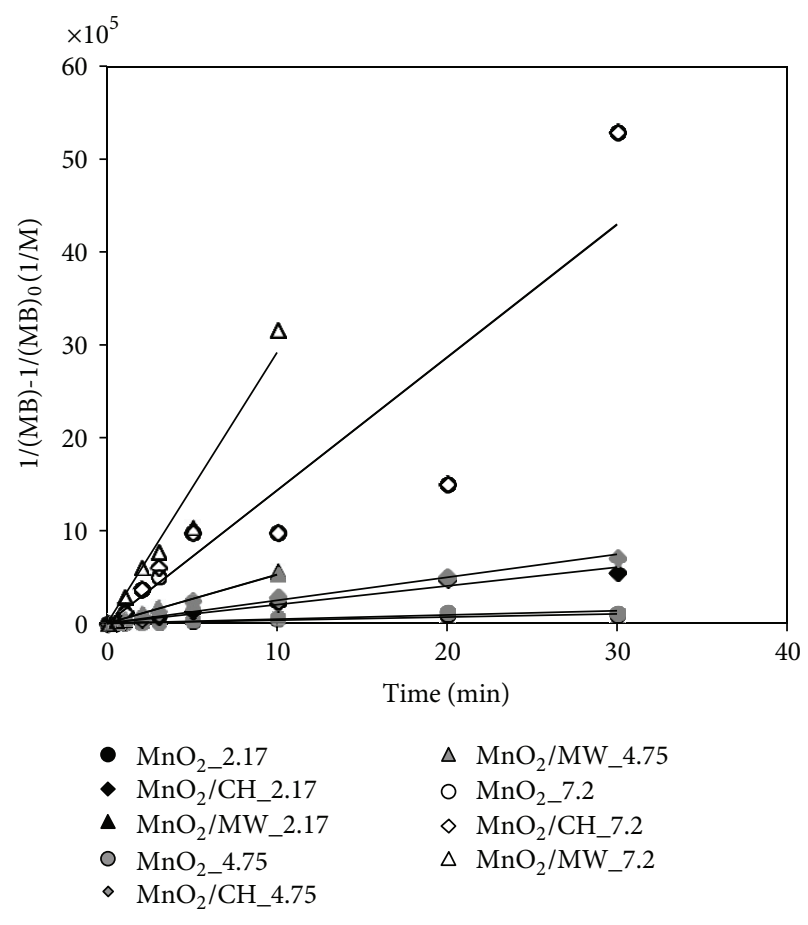

Figure 4: Plot of 1/[AMO] versus time for AMO degradation, $\left[\mathrm{MnO}_{2}\right]=2 \mathrm{~g} / \mathrm{L}(0.0023 \mathrm{M})$, and $[\mathrm{MB}]=10 \mathrm{mg} / \mathrm{L}(31.297 \mu \mathrm{M})$. The slope and correlation coefficient of regression line are displayed in Table 3.

forms a precursor of surface complex. Electrons transfer from the organic compound to the surface bound $\mathrm{Mn}(\mathrm{IV})$ on the $\mathrm{MnO}_{2}$ solid surface, subsequently resulting in the release of organic oxidation products and $\mathrm{Mn}$ (II) reductively dissolved from $\mathrm{MnO}_{2}$ into bulk solution. In such condition, $\mathrm{MnO}_{2}$ plays the role of the oxidant in reaction. Nevertheless, $\mathrm{Mn}$ (II) could be oxidized by dissolved oxygen (DO) in solution to form $\mathrm{Mn}(\mathrm{IV})$ (hydro)oxide precipitates again. In this condition, $\mathrm{MnO}_{2}$ serves as the role of catalyst and $\mathrm{DO}$ acts as the oxidant in reaction. The role of $\mathrm{MnO}_{2}$ depends on the occurrence rate of $\mathrm{Mn}$ (II) oxidation [31]. $\mathrm{Mn}$ (II) is not oxidized by molecule oxygen for several years, unless mineral surfaces or microorganisms catalyze this slow redox reaction [32]. Therefore, the solution $\mathrm{pH}$ beyond the $\mathrm{pH}_{z p c}$ promotes the readsorption of free $\mathrm{Mn}$ (II) ions in solution back onto $\mathrm{MnO}_{2}$ surface, on which it leads to the surface catalytic oxidation [22].

The rate constant for the degradation of $\mathrm{MB}$ using sole $\mathrm{MnO}_{2}, \mathrm{MnO}_{2} / \mathrm{CH}$, and $\mathrm{MnO}_{2} / \mathrm{MW}$ was determined for $\mathrm{pH}$ 2.17, 4.75, and 7.20. Figure 3 shows the kinetics of $M B$ degradation as a third-order (second upon $\mathrm{MB}$ and first upon $\mathrm{MnO}_{2}$ ) model for various conditions, as shown in

$$
\begin{aligned}
-\frac{d[\mathrm{MB}]}{d t} & =k_{\mathrm{obs}}^{\prime}[\mathrm{MB}]^{2}=k_{\mathrm{obs}}[\mathrm{MB}]^{2}\left[\mathrm{MnO}_{2}\right] \\
& =k[\mathrm{MB}]^{2}\left[\mathrm{MnO}_{2}\right]\left\{\mathrm{H}^{+}\right\}^{n} .
\end{aligned}
$$


TABLE 3: The linear equation and correlation coefficient of regression line in Figure 4.

\begin{tabular}{|c|c|c|c|}
\hline System & Linear equation & Correlation coefficient & $t$ value $^{*}$ \\
\hline $\mathrm{MnO}_{2} \mathrm{p} \mathrm{pH} 2.17$ & $y=3383 x$ & 0.951 & 0.80 \\
\hline $\mathrm{MnO}_{2} / \mathrm{CH} \_\mathrm{pH} 2.17$ & $y=20216 x$ & 0.986 & 0.77 \\
\hline $\mathrm{MnO}_{2} / \mathrm{MW} \_\mathrm{pH} 2.17$ & $y=52543 x$ & 0.983 & -0.65 \\
\hline $\mathrm{MnO}_{2-\mathrm{pH}} 4.75$ & $y=4599 x$ & 0.939 & 0.92 \\
\hline $\mathrm{MnO}_{2} / \mathrm{CH} \_\mathrm{pH} 4.75$ & $y=24858 x$ & 0.977 & 1.58 \\
\hline $\mathrm{MnO}_{2} / \mathrm{MW} \_\mathrm{pH} 4.75$ & $y=52337 x$ & 0.996 & -0.05 \\
\hline $\mathrm{MnO}_{2-\mathrm{pH}} 7.20$ & $y=143080 x$ & 0.926 & -0.26 \\
\hline $\mathrm{MnO}_{2} / \mathrm{CH} \_\mathrm{pH} 7.20$ & $y=143312 x$ & 0.925 & -0.20 \\
\hline $\mathrm{MnO}_{2} / \mathrm{MW} \_\mathrm{pH} 7.20$ & $y=291677 x$ & 0.981 & -0.71 \\
\hline
\end{tabular}

All $P \geq 0.05$.

TABLE 4: Third-order rate constants $k_{\mathrm{obs}}$ in $\mathrm{L}^{2} \mathrm{~mol}^{-2} \mathrm{~s}^{-1}$ for the degradation of $\mathrm{MB}$ by $\mathrm{MnO}_{2}$.

\begin{tabular}{lccc}
\hline $\mathrm{pH}$ & \multicolumn{3}{l}{$\log k_{\text {obs }}$} \\
& $\mathrm{MnO}_{2}$ & $\mathrm{MnO}_{2} / \mathrm{CH}$ & $\mathrm{MnO}_{2} / \mathrm{MW}$ \\
\hline 2.71 & 6.17 & 6.94 & 7.36 \\
4.75 & 6.30 & 7.03 & 7.36 \\
7.20 & 7.79 & 7.79 & 8.53 \\
\hline
\end{tabular}

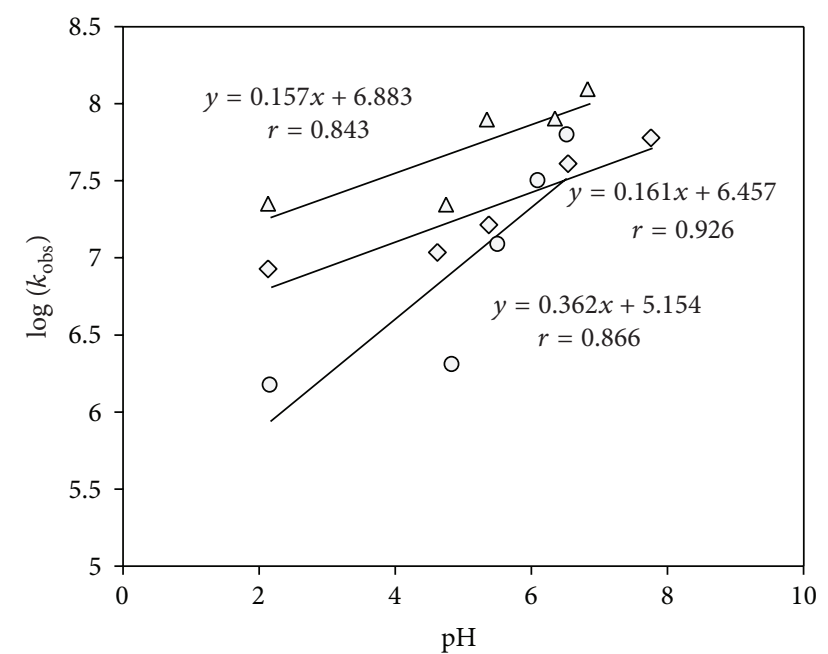
$\triangle \mathrm{MnO}_{2} / \mathrm{MW}$
$\diamond \mathrm{MnO}_{2} / \mathrm{CH}$
$\bigcirc \mathrm{MnO}_{2}$

FIGURE 5: Dependence of the third-order rate constant $k_{\mathrm{obs}}$ on $\mathrm{pH}$; $\left[\mathrm{MnO}_{2}\right]=0.023 \mathrm{M},[\mathrm{MB}]=31.3 \mu \mathrm{M}$.

The kinetics were modeled assuming a second-order reaction with respect to $\mathrm{MB}$, which was verified by plotting $1 /[\mathrm{MB}]$ as a function of the reaction time with a slope of $k_{\text {obs }}^{\prime}$ (Figure 4 and Table 3). A statistical approach is more appropriate than correlation coefficient to determine "goodness of fit" of a model for experimental data [33]. The paired $t$-test was used to examine the difference between the observed and the predicted variable, with a significant level of 0.05 . As Table 3 showed, the results of paired $t$-test suggest that in all systems the observed and predicted variables $\left(1 /[\mathrm{MB}]-1 /[\mathrm{MB}]_{0}\right)$ did not reveal significant difference (all $P \geq 0.05$ ), confirming the third-order kinetic model is of statistically reasonable for this reaction. Assuming a first-order reaction with respect to this $\mathrm{MnO}_{2}$ because of the constant concentration of $\mathrm{MnO}_{2}$, the rate constants $k_{\text {obs }}$ in $\mathrm{L}^{2} \mathrm{~mol}^{-2} \mathrm{~s}^{-1}$ were then calculated and are shown in Table 4 . Values of $\log k_{\text {obs }}$ are plotted as a function of $\mathrm{pH}$ in Figure 5. The apparent reaction order with respect to $\mathrm{H}^{+}$was determined as the slope of the straight line $\log k_{\mathrm{obs}}=$ $f(\mathrm{pH})$, and equal to $0.362,0.161$, and 0.157 for sole $\mathrm{MnO}_{2}$, $\mathrm{MnO}_{2} / \mathrm{CH}$, and $\mathrm{MnO}_{2} / \mathrm{MW}$, respectively. The rate constant $k$ for (2) was calculated to be $1.76 \times 10^{5}, 3.50 \times 10^{5}$, and $8.92 \times 10^{5} \mathrm{M}^{-1.7} \mathrm{~s}^{-1}$ for the system of sole $\mathrm{MnO}_{2}, \mathrm{MnO}_{2} / \mathrm{CH}$, and $\mathrm{MnO}_{2} / \mathrm{MW}$, respectively. The relative effects of $\mathrm{MW}$ on $\mathrm{MB}$ degradation are twofold. As the rate constant revealed, energy application considerably enhances the rate of $\mathrm{MB}$ degradation using $\mathrm{MnO}_{2}$. The rate constant of the system heated at $50^{\circ} \mathrm{C}\left(\mathrm{MnO}_{2} / \mathrm{CH}\right)$ increases two times than that of the sole $\mathrm{MnO}_{2}$ system, and $200 \mathrm{~W}$ MW irradiation drastically elevates 5.1 times the degradation rate of $\mathrm{MB}$ using $\mathrm{MnO}_{2}$. Figure 1 shows that the solution temperature reached $50^{\circ} \mathrm{C}$ in 10 min under $200 \mathrm{~W}$ MW irradiation, meaning that during the reaction period of the $\mathrm{MnO}_{2} / \mathrm{MW}$ system, the solution temperature is lower than $50^{\circ} \mathrm{C}$ most of the time. The second influence of $\mathrm{MW}$ on $\mathrm{MB}$ degradation using $\mathrm{MnO}_{2}$ consists in the alleviation of $\mathrm{pH}$ dependence. The kinetics of $\mathrm{MB}$ degradation using $\mathrm{MnO}_{2}$ show a significant $\mathrm{pH}$-dependence with a stoichiometry of 0.362 ; however, its value declines to 0.157 for the $\mathrm{MnO}_{2} / \mathrm{MW}$ system (Figure 5). Although the $\mathrm{pH}$ elevation increases the amount of the negative-charged site and, consequently, promotes the adsorption of cationic MB molecules, the MW application leads to a more efficient MB degradation in low $\mathrm{pH}$ circumstances.

3.4. Blue-Shift of Absorbance Peak for Dye Solution with Time. To compare the progression of $\mathrm{MB}$ degraded using $\mathrm{MnO}_{2}$ under various conditions, UV-vis spectroscopy was used to identify the organic compounds in the solution. Because the reaction is too quick under $\mathrm{pH} 7.20$ and too slow under $\mathrm{pH} 2.17$, to clearly distinguish the curve differences, the evolution of absorbance peaks with time were discussed with the case conducted at a $\mathrm{pH}$ of 4.75 . Figure 6 shows the absorbance measurements obtained in various reaction times 


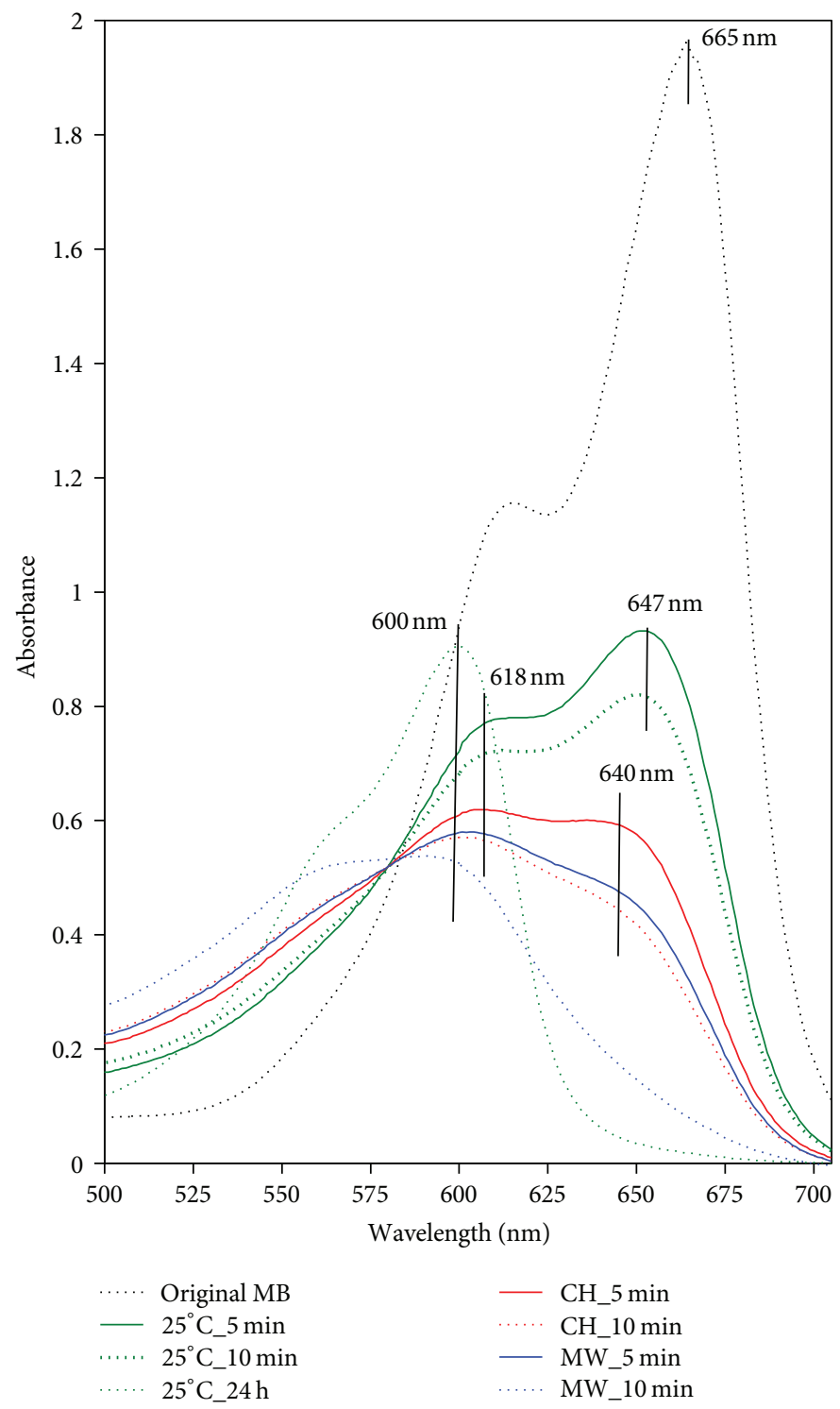

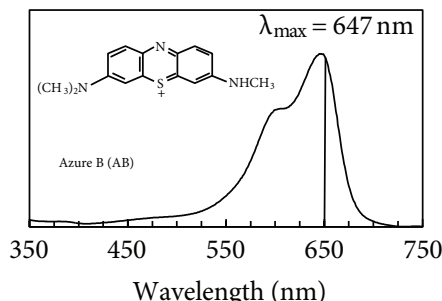

(b)

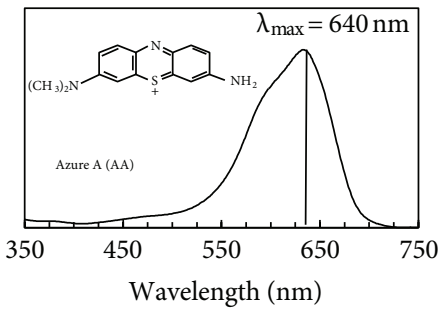

(c)

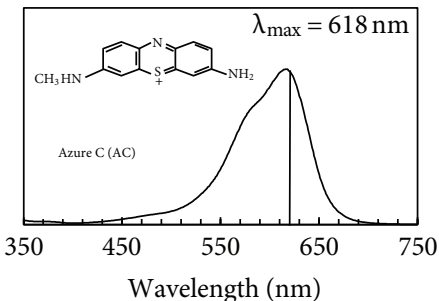

(d)

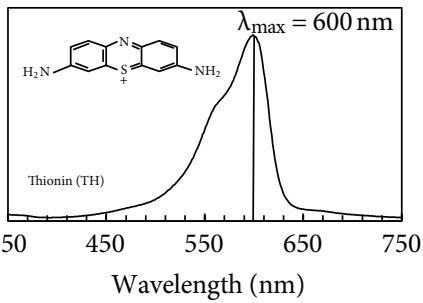

(e)

FIGURE 6: (a) UV-vis spectroscopy of MB after different reaction times under various radiation conditions, compared to (b) AB, (c) AA, (d) $\mathrm{AC}$, and (e) TH standard compounds in aqueous solution.

at $\mathrm{pH} 4.75$ compared with possible intermediary-degradation compounds. The UV-vis characteristic peak $\left(\lambda_{\max }\right)$ for azure $\mathrm{B}(\mathrm{AB})$, azure $\mathrm{A}(\mathrm{AA})$, azure $\mathrm{C}(\mathrm{AC})$, and Thionin $(\mathrm{TH})$ was $650,640,618$, and $600 \mathrm{~nm}$, respectively, and is shown in Figures 6(b) to 6(e). In the sole $\mathrm{MnO}_{2}$ system (temperature controlled at $25^{\circ} \mathrm{C}$ ), the UV-vis absorbance peak for the dye solution shifts from $665 \mathrm{~nm}\left(\lambda_{\max }\right.$ for MB) to $650 \mathrm{~nm}\left(\lambda_{\max }\right.$ for $\mathrm{AB}$ ) at a reaction time of $5 \mathrm{~min}$ and is retained at the same wavelength with intensity descent in the system with a reaction time of $10 \mathrm{~min}$. However, the absorbance peak shifts to $600 \mathrm{~nm}\left(\lambda_{\max }\right.$ for $\left.\mathrm{TH}\right)$ at a reaction time prolonged to $24 \mathrm{~h}$. In the $\mathrm{MnO}_{2} / \mathrm{CH}$ system, two distinguishable absorbance peaks at $640 \mathrm{~nm}\left(\lambda_{\max }\right.$ for AA) and $618 \mathrm{~nm}\left(\lambda_{\max }\right.$ for AC) were observed at $5 \mathrm{~min}$. At $10 \mathrm{~min}$ of reaction time, only the peak of $618 \mathrm{~nm}$ remained with an abating peak intensity. The absorbance peaks in the $\mathrm{MnO}_{2} / \mathrm{MW}$ system show a more marked blue-shift and less intensity compared to that of the sole $\mathrm{MnO}_{2}$ and $\mathrm{MnO}_{2} / \mathrm{CH}$ systems at the same reaction time. The absorbance peak appears at $618 \mathrm{~nm}\left(\lambda_{\max }\right.$ for AC) and $600 \mathrm{~nm}\left(\lambda_{\max }\right.$ for TH) for $5 \mathrm{~min}$ and $10 \mathrm{~min}$ in the $\mathrm{MnO}_{2} / \mathrm{MW}$ system, respectively. Zhang et al. [3] indicated that, in the $\mathrm{TiO}_{2}$ photocatalyzed system, the peak $665 \mathrm{~nm}$ of MB blue shifted by as much as 20 to $650 \mathrm{~nm}$; this shows the $\mathrm{N}$-demethylation of $\mathrm{MB}$. Our previous study showed that, in a $\mathrm{MnO}_{2}$ suspension system, $\mathrm{MB}$ was cleaved through $\mathrm{N}$-demethylation, in which reactions azure $\mathrm{B}(\mathrm{AB})$, azure A (AA), azure $\mathrm{C}(\mathrm{AC})$, and thionin $(\mathrm{TH})$ were stepwise generated under room temperature [22]. $N$-dealkylation of dyes containing auxochromic alkylamine groups is important for catalytic degradation. The color of the MB solution turned 
less intense during the gradual degradation of all or part of the auxochromic groups (methyl or methylamine) with time evolution. In the sole $\mathrm{MnO}_{2}$ system, $\mathrm{MB}$ was catalytically degraded to $\mathrm{TH}$ until $24 \mathrm{~h}$ of reaction time. In contrast, $\mathrm{MW}$ significantly enhanced this degradation process in $\mathrm{MnO}_{2}$ suspensions and shortened the duration from $24 \mathrm{~h}$ to $10 \mathrm{~min}$. A less intense absorbance peak at $600 \mathrm{~nm}$ was coherently observed in $\mathrm{MnO}_{2} / \mathrm{MW}$.

Briefly, for a chemical reaction to occur, it is necessary to activate the reactants. Heating is a conventional method in chemistry to activate a reactive medium. The elevation of temperature induces an increment of kinetic energy in molecules and, consequently, enhances the collision rate. However, among these collisions, only a few have sufficient energy and the proper orientation to lead to the product. Heating causes an isotropic excitation of molecules, and that is why all collisions are inefficient. According to the Eyring formulation, an excitation tool that would be able to favor efficient collisions by modifying the energy distribution of molecules (i.e., an anisotropic excitation) could enhance the reaction rate. At identical temperatures of a reaction medium (i.e., the same average value of the energy distribution), but for different distributions of the kinetic energies of molecules, different reaction rates could be observed. Athermal effects in chemistry have been partially based on this premise. Under MW irradiation, $\mathrm{MnO}_{2}$, a strong microwave absorbent, can significantly absorb and transfer MW energy, indicating that a strong absorbent could engender large amounts of "hot spots," which could enhance the degradation of molecules $[1,7]$. The electrophilic oxygen ions $\left(\mathrm{O}_{2}^{-}, \mathrm{O}^{-}\right.$, and $\left.\mathrm{O}^{2-}\right)$ that are derived from lattice oxygen on $\mathrm{MnO}_{2}$ show high activity in catalytic reactions and could participate in the degradation of MB [22]. The vacancies of lattice oxygen are lately replenished by molecular oxygen dissolved in solution, which is known as the Mars van Krevelen mechanism [34].

Because the energy of microwave photons is too low (approximately $10^{-5} \mathrm{ev}$ ) compared to chemical bonds, no breaking of chemical bonds can be induced by absorption of microwave photons. Therefore, MW cannot induce any shifting in chemical equilibrium but can accelerate the rate of MB degraded. As shown in Figure 4, MB was degraded to the $\mathrm{TH}$ in $5 \mathrm{~min}$ for the $\mathrm{MnO}_{2} / \mathrm{MW}$ system, $10 \mathrm{~min}$ for the $\mathrm{MnO}_{2} / \mathrm{CH}$ system, and $24 \mathrm{~h}$ for the sole $\mathrm{MnO}_{2}$ system. This implies that the simultaneous combination of microwave and $\mathrm{MnO}_{2}$ can effectively degrade $\mathrm{MB}$ and its intermediates (i.e., $\mathrm{AB}, \mathrm{AA}, \mathrm{AC}$, and $\mathrm{TH}$ ) produced in the process of $\mathrm{MB}$ degradation, eventually driving the intermediates to total mineralization.

Although this study focused on the kinetics of MB degradation, the equilibrium of reaction could be discussed by comparing the final state conducted under room temperature with that under $\mathrm{CH}$. The chemical equilibrium will shift to counteract an imposed change in temperature, according to Le Chateller's principle. As Figure 3 showed, both sole $\mathrm{MnO}_{2}$ and $\mathrm{MnO}_{2} / \mathrm{CH}$ system the $\mathrm{MB}$ degradation approximately approached pseudoequilibrium at $20 \mathrm{~min}$; therefore, the reaction results at $30 \mathrm{~min}$ were considered as the equilibrium state. The amount of remained $\mathrm{MB}$ for $\mathrm{MnO}_{2} / \mathrm{CH}$ system

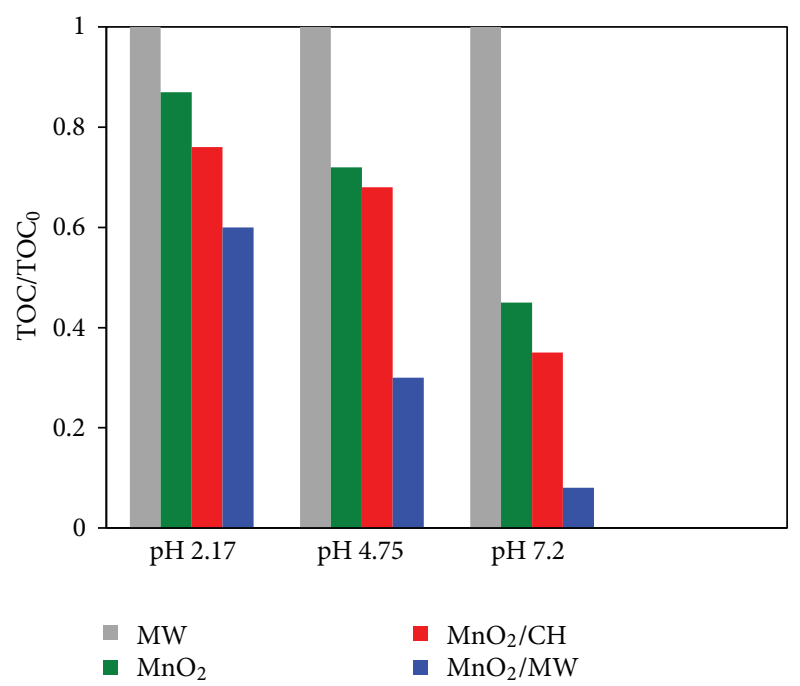

FIgURE 7: Ratio of remaining TOC at $10 \mathrm{~min}$ to original TOC $\left(\mathrm{TOC}_{0}\right)$ for dye solution. $[\mathrm{MB}]=10 \mathrm{mg} / \mathrm{L},\left[\mathrm{MnO}_{2}\right]=2 \mathrm{~g} / \mathrm{L}$, reaction time $10 \mathrm{~min}$, and solution $\mathrm{pH} 4.75$.

is lower than that for sole $\mathrm{MnO}_{2}$ (conducted at room temperature) under all $\mathrm{pH}$ conditions employed. This result suggests that the degradation of $\mathrm{MB}$ using $\mathrm{MnO}_{2}$ could be an endothermic reaction, which was also corroborated by the literatures $[14,35]$.

3.5. Total Organic Carbon (TOC) Analysis. To gain insights into overall pollutant removal and mineralization, TOC analysis was conducted to evaluate the decontamination of all residual carbon-containing metabolites more appropriately $[36,37]$. The TOC of the original $10 \mathrm{mg} \mathrm{MB} \mathrm{L}^{-1}$ solution was $5.71 \mathrm{mg} \mathrm{TOC} \mathrm{L}^{-1}$, which coincides with the theoretical calculation of total carbon for an $\mathrm{MB}$ molecule $\left(6 \mathrm{mg} \mathrm{TOC} \mathrm{L}^{-1}\right)$. Figure 7 shows the ratio of the remaining TOC (TOC) to original TOC $\left(\mathrm{TOC}_{0}\right)$ in dye solution with varying $\mathrm{pH}$ at $10 \mathrm{~min}$ for various testing conditions. The MB solution irradiated under MW for $10 \mathrm{~min}$ shows no TOC descent, indicating that sole MW energy is insufficient to break and mineralize an $\mathrm{MB}$ molecule. In the $\mathrm{MnO}_{2}$ suspension systems without any irradiation, the ratio of $\mathrm{TOC} / \mathrm{TOC}_{0}$ decreases when $\mathrm{pH}$ increases. This result is in agreement with that of UV-vis, as shown in Figure 3. Because the precursor complex formation or the adsorption reaction of organics onto an $\mathrm{MnO}_{2}$ surface is crucial for all heterogeneous solid/solution reactions, this result could be ascribed to the increase of positively charged sites on $\mathrm{MnO}_{2}$ elevating the adsorption of cationic molecules, including original $\mathrm{MB}$ and its intermediates $\mathrm{AB}, \mathrm{AA}, \mathrm{AC}$, and $\mathrm{TH}$, and then consequently promote mineralization. Although no specific UV-vis peak is observed for the MB solution after reaction with sole $\mathrm{MnO}_{2}$ at $\mathrm{pH} 7.20$ (figure not shown), the TOC in the solution still remained as high as approximately $45 \%$. These results might show that at a $\mathrm{pH}$ of 7.20, MB is degraded to compounds that are colorless in UV-vis; however, some small organic compounds that may not have been detected using UV-vis contributed to the 
remaining TOC in the sole $\mathrm{MnO}_{2}$ case. By contrast, $\mathrm{CH}$ and MW could significantly enhance TOC degradation in $\mathrm{MnO}_{2}$ suspensions. The TOC removal in the $\mathrm{MnO}_{2} / \mathrm{MW}$ system at $\mathrm{pH} 7.20$ for $10 \mathrm{~min}$ is approximately $92 \%$. Although increasing temperatures could reverse the adsorption of $\mathrm{MB}$ and its intermediates onto $\mathrm{MnO}_{2}$, the advantages of great amounts of electrophilic oxygen ions derived from a $\mathrm{MnO}_{2}$ lattice under MW irradiation catalyzing MB into mineralization appear to overcome the disadvantage of adsorption inhibitions.

\section{Conclusion}

The degradation of $\mathrm{MB}$ using $\mathrm{MW}$-enhanced $\mathrm{MnO}_{2}$ was significantly higher than that using sole $\mathrm{MnO}_{2}$ or $\mathrm{CH}$-enhanced $\mathrm{MnO}_{2}$. The degradation kinetics of $\mathrm{MB}$, including three tested systems (sole $\mathrm{MnO}_{2}, \mathrm{MnO}_{2} / \mathrm{CH}$, and $\mathrm{MnO}_{2} / \mathrm{MW}$ ), fits a third-order (second upon $\mathrm{MB}$ and first upon $\mathrm{MnO}_{2}$ ) kinetic model well and is pronouncedly $\mathrm{pH}$ dependent. However, the rate constant $k$ of MB degradation is $1.76 \times$ $10^{5}, 3.50 \times 10^{5}$, and $8.92 \times 10^{5} \mathrm{M}^{-1.7} \mathrm{~s}^{-1}$ for the systems of sole $\mathrm{MnO}_{2}, \mathrm{MnO}_{2} / \mathrm{CH}$, and $\mathrm{MnO}_{2} / \mathrm{MW}$, respectively. $\mathrm{MB}$ was stepwise degraded to $\mathrm{AB}, \mathrm{AA}, \mathrm{AC}$, and $\mathrm{TH}$ and finally mineralized to $\mathrm{CO}_{2}$ and $\mathrm{H}_{2} \mathrm{O}$. MW irradiation noticeably accelerates $\mathrm{MB}$ degradation but does not induce any shifting in chemical equilibrium. The enhancement of MW on MB degradation using $\mathrm{MnO}_{2}$ could be caused by the stronger MW adsorbent markedly absorbing microwave energy and generating abundant electrophilic oxygen ions $\left(\mathrm{O}_{2}{ }^{-}, \mathrm{O}^{-}\right.$, and $\mathrm{O}^{2-}$ ) to degrade $\mathrm{MB}$.

\section{Conflict of Interests}

The authors declare no competing financial interests and no direct financial relation with the commercial identity mentioned in this paper.

\section{Acknowledgment}

The authors thank the National Science Council of Taiwan, China, NSC 95-2622-E-131-008-CC3 and NSC 96-2628-E131-001-MY3 for financial support.

\section{References}

[1] L. Zhang, X. Zhou, X. Guo, X. Song, and X. Liu, "Investigation on the degradation of acid fuchsin induced oxidation by $\mathrm{MgFe}_{2} \mathrm{O}_{4}$ under microwave irradiation," Journal of Molecular Catalysis A, vol. 335, no. 1-2, pp. 31-37, 2011.

[2] M. Wainwright, D. A. Phoenix, L. Rice, S. M. Burrow, and J. Waring, "Increased cytotoxicity and phototoxicity in the methylene blue series via chromophore methylation," Journal of Photochemistry and Photobiology B, vol. 40, no. 3, pp. 233-239, 1997.

[3] T. Zhang, T. Oyama, S. Horikoshi, H. Hidaka, J. Zhao, and N. Serpone, "Photocatalyzed N-demethylation and degradation of methylene blue in titania dispersions exposed to concentrated sunlight," Solar Energy Materials and Solar Cells, vol. 73, no. 3, pp. 287-303, 2002.
[4] N. Matsuda, J. Zheng, D. K. Qing, A. Takatsu, and K. Kato, "In situ absorption spectra and adsorbed species of methylene blue on glass/water interfaces by slab optical waveguide spectroscopy," Applied Spectroscopy, vol. 57, no. 1, pp. 100-103, 2003.

[5] A. N. Chowdhury, M. S. Azam, M. Aktaruzzaman, and A. Rahim, "Oxidative and antibacterial activity of $\mathrm{Mn}_{3} \mathrm{O}_{4}$," Journal of Hazardous Materials, vol. 172, no. 2-3, pp. 1229-1235, 2009.

[6] J. Tang, Z. Zou, J. Yin, and J. Ye, "Photocatalytic degradation of methylene blue on $\mathrm{CaIn}_{2} \mathrm{O}_{4}$ under visible light irradiation," Chemical Physics Letters, vol. 382, no. 1-2, pp. 175-179, 2003.

[7] C. Marún, L. Daniel Conde, and L. Steven Suib, "Catalytic oligomerization of methane via microwave heating," Journal of Physical Chemistry A, vol. 103, no. 22, pp. 4332-4340, 1999.

[8] N. Moloto, S. Mpelane, L. M. Sikhwivhilu, and S. S. Ray, "Optical and morphological properties of $\mathrm{ZnO}$ - and $\mathrm{TiO}_{2}$ derived nanostructures synthesized via a microwave-assisted hydrothermal method," International Journal of Photoenergy, vol. 2012, Article ID 189069, 6 pages, 2012.

[9] E. T. Thostenson and T. W. Chou, "Microwave processing: fundamentals and applications," Composites Part A, vol. 30, no. 9, pp. 1055-1071, 1999.

[10] D. A. C. Stuerga and P. Gaillard, "Microwave athermal effects in chemistry: a myth's autopsy. Part I: historical background and fundamentals of wave-matter interaction," Journal of Microwave Power and Electromagnetic Energy, vol. 31, no. 2, pp. 87-100, 1996.

[11] K. A. Malinger, Y. S. Ding, S. Sithambaram, L. Espinal, S. Gomez, and S. L. Suib, "Microwave frequency effects on synthesis of cryptomelane-type manganese oxide and catalytic activity of cryptomelane precursor," Journal of Catalysis, vol. 239, no. 2, pp. 290-298, 2006.

[12] H. Sandin, M. L. Swanstein, and E. Wellner, "A fast and parallel route to cyclic isothioureas and guanidines with use of microwave-assisted chemistry," Journal of Organic Chemistry, vol. 69, no. 5, pp. 1571-1580, 2004.

[13] I. Forrez, M. Carballa, G. Fink et al., "Biogenic metals for the oxidative and reductive removal of pharmaceuticals, biocides and iodinated contrast media in a polishing membrane bioreactor," Water Research, vol. 45, no. 4, pp. 1763-1773, 2011.

[14] K. M. Parida, S. Sahu, K. H. Reddy, and P. C. Sahoo, "A kinetic, thermodynamic, and mechanistic approach toward adsorption of methylene blue over water-washed manganese nodule leached residues," Industrial and Engineering Chemistry Research, vol. 50, no. 2, pp. 843-848, 2011.

[15] S. L. Suib, "Structure, porosity, and redox in porous manganese oxide octahedral layer and molecular sieve materials," Journal of Materials Chemistry, vol. 18, no. 14, pp. 1623-1631, 2008.

[16] M. Minakshi, "Alkaline-earth oxide modified $\mathrm{MnO}_{2}$ cathode: enhanced performance in an aqueous rechargeable battery," Industrial and Engineering Chemistry Research, vol. 50, no. 14, pp. 8792-8795, 2011.

[17] M. A. Rauf, M. A. Meetani, A. Khaleel, and A. Ahmed, "Photocatalytic degradation of methylene blue using a mixed catalyst and product analysis by LC/MS," Chemical Engineering Journal, vol. 157, no. 2-3, pp. 373-378, 2010.

[18] J. Liu, Y. Yu, Z. Liu, S. Zuo, and B. Li, "AgBr-coupled $\mathrm{TiO}_{2}$ : a visible heterostructured photocatalyst for degrading dye pollutants," International Journal of Photoenergy, vol. 2012, Article ID 254201, 7 pages, 2012. 
[19] P. Luo, Y. Zhao, B. Zhang, J. Liu, Y. Yang, and J. Liu, "Study on the adsorption of neutral red from aqueous solution onto halloysite nanotubes," Water Research, vol. 44, no. 5, pp. 1489-1497, 2010.

[20] M. Mohamed and E. S. Aazam, "Synthesis and characterization of $\mathrm{CeO}_{2}-\mathrm{SiO}_{2}$ nanoparticles by microwave-assisted irradiation method for photocatalytic oxidation of methylene blue dye," International Journal of Photoenergy, vol. 2012, Article ID 928760, 9 pages, 2012.

[21] M. Zaied, S. Peulon, N. Bellakhal, B. Desmazières, and A. Chaussé, "Studies of N-demethylation oxidative and degradation of methylene blue by thin layers of birnessite electrodeposited onto $\mathrm{SnO}_{2}$," Applied Catalysis B, vol. 101, no. 3-4, pp. 441-450, 2011.

[22] W. H. Kuan and Y. C. Chan, "pH-dependent mechanisms of methylene blue reacting with tunneled manganese oxide pyrolusite," Journal of Hazardous Materials, vol. 239-240, pp. 152-159, 2012.

[23] M. X. Zhu, Z. Wang, and L. Y. Zhou, "Oxidative decolorization of methylene blue using pelagite," Journal of Hazardous Materials, vol. 150, no. 1, pp. 37-45, 2008.

[24] V. R. K. Murthy, T. A. Prasada Rao, and J. Sobhanadri, "Dielectric properties of some dyes in the radio-frequency region," Journal of Physics D, vol. 10, no. 17, article 013, pp. 2405-2409, 1977.

[25] W. M. Haynes and D. R. Lide, CRC Handbook of Chemistry Physics, Taylor \& Francis, London, UK, 91st edition, 2010.

[26] W. Zhang, H. L. Tay, S. S. Lim, Y. Wang, Z. Zhong, and R. $\mathrm{Xu}$, "Supported cobalt oxide on MgO: highly efficient catalysts for degradation of organic dyes in dilute solutions," Applied Catalysis B, vol. 95, no. 1-2, pp. 93-99, 2010.

[27] W. H. Kuan, C. Y. Chen, and C. Y. Hu, "Removal of methylene blue from water by $\gamma-\mathrm{MnO}_{2}$," Water Science and Technology, vol. 64, pp. 899-903, 2011.

[28] W. H. Kuan, S. L. Lo, and M. K. Wang, "Modeling and electrokinetic evidences on the processes of the $\mathrm{Al}(\mathrm{III})$ sorption continuum in $\mathrm{SiO}_{2(s)}$ suspension," Journal of Colloid and Interface Science, vol. 272, no. 2, pp. 489-497, 2004.

[29] H. Zhang, W. R. Chen, and C. H. Huang, "Kinetic modeling of oxidation of antibacterial agents by manganese oxide," Environmental Science and Technology, vol. 42, no. 15, pp. 5548-5554, 2008.

[30] W. Stumm, Chemistry of the Solid-Water Interface: Processes at the Mineral-Water and Particle-Water Interface in Natural Systems, John Wiley and Sons, New York, NY, USA, 1992.

[31] A. T. Stone, "Reductive dissolution of manganese(III/IV) oxides by substituted phenols," Environmental Science and Technology, vol. 21, no. 10, pp. 979-988, 1987.

[32] W. Sung and J. J. Morgan, "Oxidative removal of $\mathrm{Mn}$ (II) from solution catalysed by the $\gamma$ - $\mathrm{FeOOH}$ (lepidocrocite) surface," Geochimica et Cosmochimica Acta, vol. 45, no. 12, pp. 2377-2383, 1981.

[33] M. E. Davis and R. J. Davis, Fundamentals of Chemical Reaction Engineering, McGraw-Hill Higher Education, New York, NY, USA, 2003.

[34] C. Doornkamp and V. Ponec, "The universal character of the Mars and Van Krevelen mechanism," Journal of Molecular Catalysis A, vol. 162, no. 1-2, pp. 19-32, 2000.

[35] T. Sriskandakumar, N. Opembe, C. H. Chen, A. Morey, C. King'Ondu, and S. L. Suib, "Green decomposition of organic dyes using octahedral molecular sieve manganese oxide catalysts," Journal of Physical Chemistry A, vol. 113, no. 8, pp. 1523-1530, 2009.
[36] H. Lachheb, E. Puzenat, A. Houas et al., "Photocatalytic degradation of various types of dyes (alizarin S, crocein orange $G$, methyl red, congo red, methylene blue) in water by UVirradiated titania," Applied Catalysis B, vol. 39, no. 1, pp. 75-90, 2002.

[37] M. A. Lemus, T. López, S. Recillas et al., "Photocatalytic degradation of 2,4-dichlorophenoxyacetic acid using nanocrystalline cryptomelane composite catalysts," Journal of Molecular Catalysis A, vol. 281, no. 1-2, pp. 107-112, 2008. 

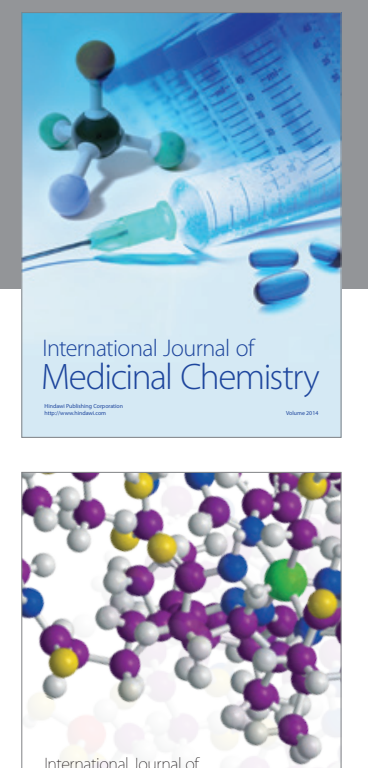

\section{Carbohydrate} Chemistry

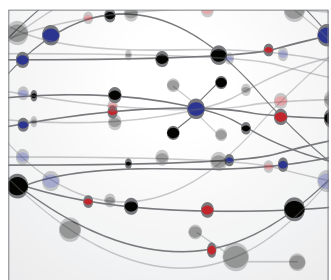

The Scientific World Journal
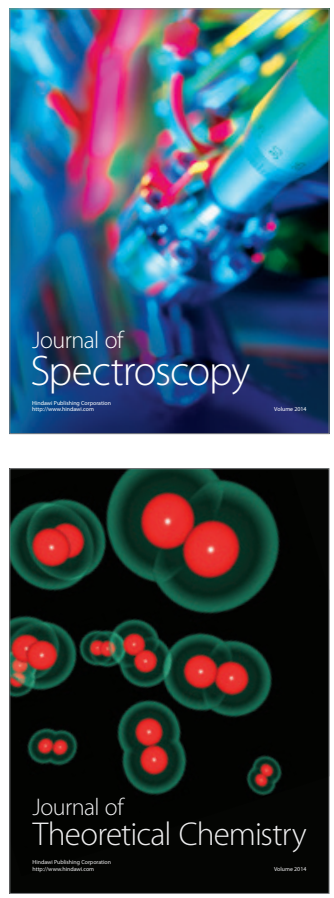
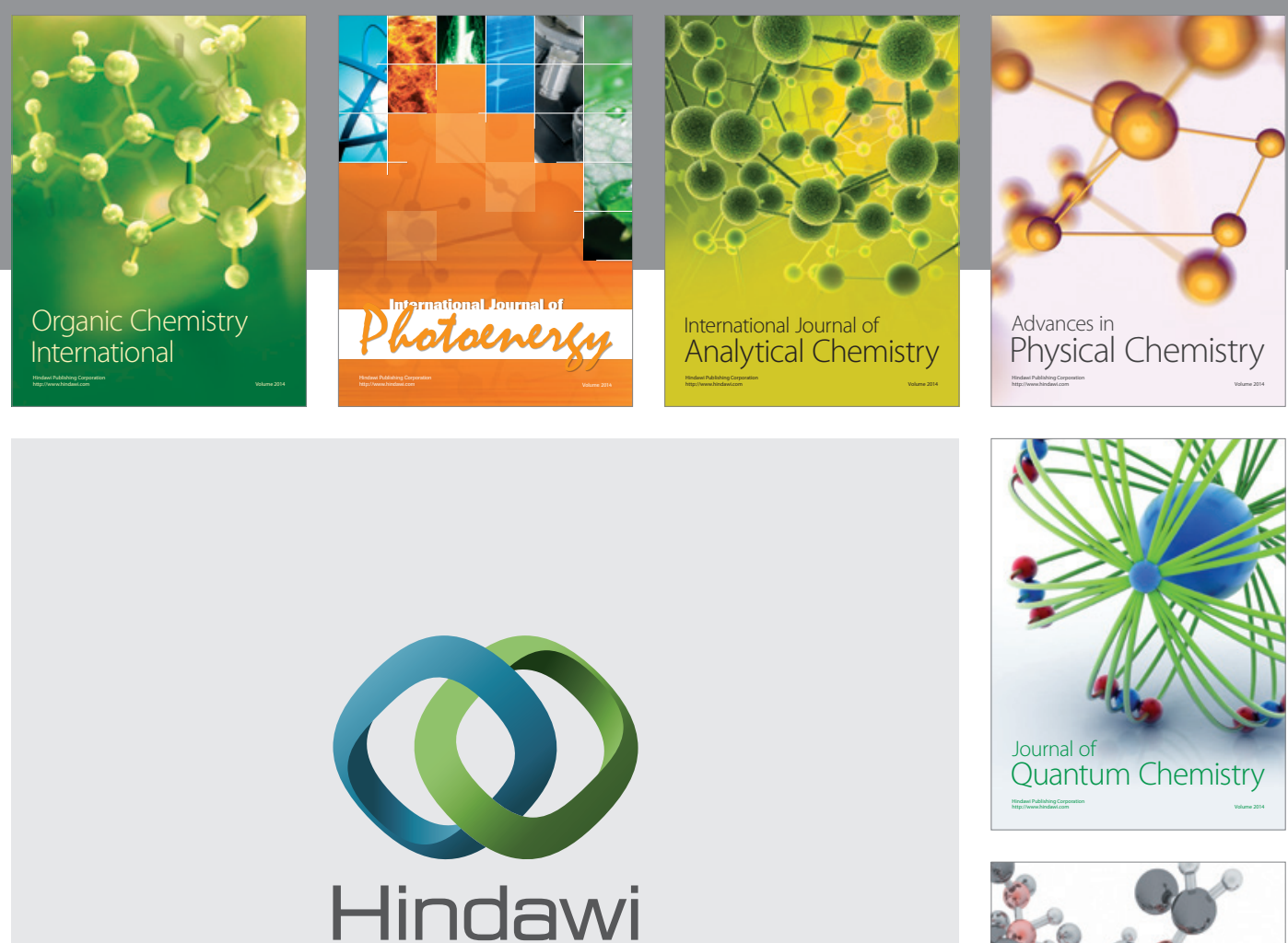

Submit your manuscripts at

http://www.hindawi.com

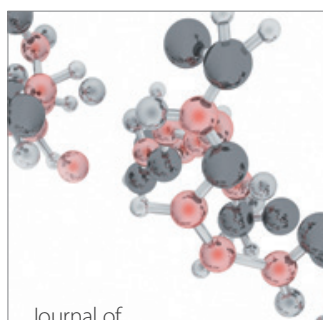

Analytical Methods

in Chemistry

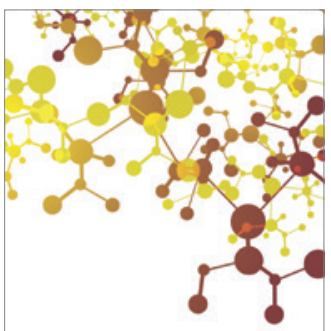

Journal of

Applied Chemistry

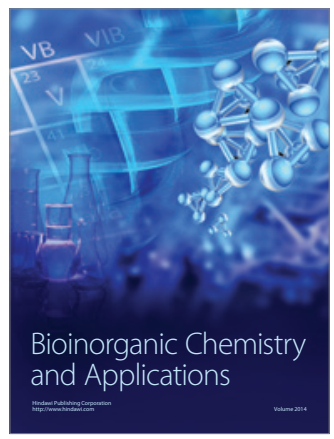

Inorganic Chemistry
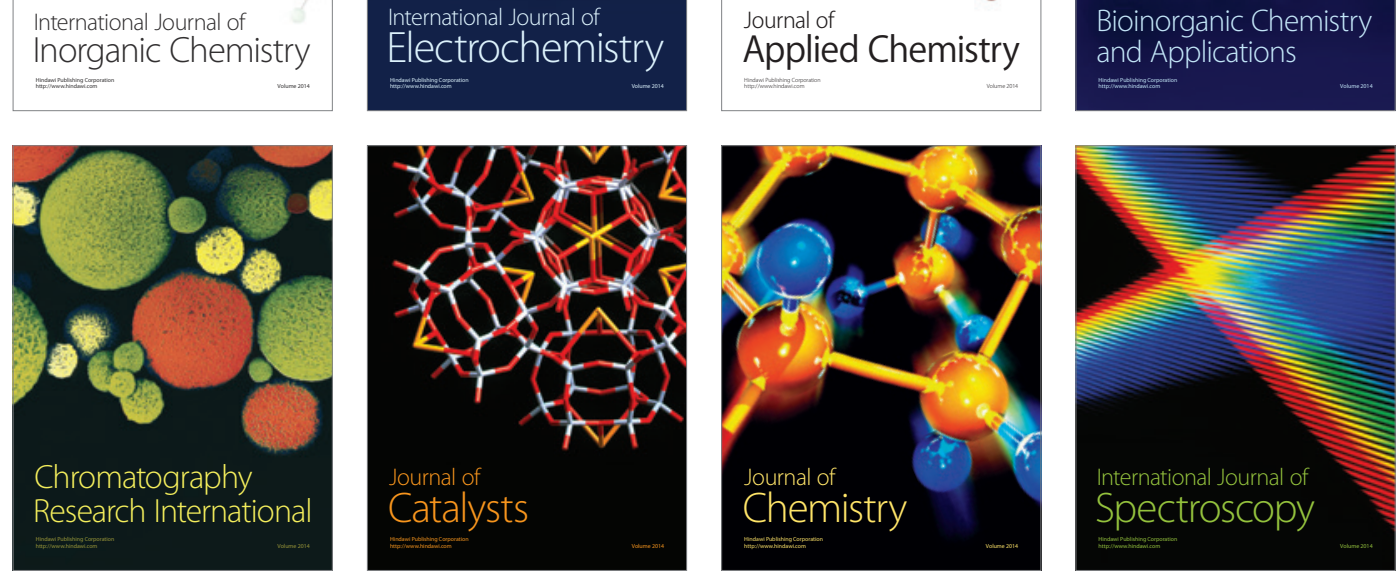